\title{
Education scholarship in Canadian emergency medicine: The past, present, and future
}

Rob Woods, MD, MMEd*; Teresa Chan, MD, HBSc, BEd, MHPE ${ }^{\dagger}$; Brent Thoma, MD, MA, MSc*; Jonathan Sherbino, MD, MEd ${ }^{\dagger}$

\section{INTRODUCTION}

In this issue of $C F E M$, Chan et al. have published part 2 of a how-to series on education scholarship methods. ${ }^{1}$ This series will serve as a great primer for those interested in getting started in education scholarship. More importantly, it serves as a reminder of how far emergency medicine (EM) education scholarship in Canada has come.

THE PAST: A RECENT HISTORY OF CANADIAN EMERGENCY MEDICINE EDUCATIONAL SCHOLARSHIP

In 2010, Sherbino published a commentary in CFEM ${ }^{2}$ that challenged the Canadian EM community to identify gaps in our educational practices and address them through research and innovation scholarship. The first Canadian Association of Emergency Physicians (CAEP) Academic Symposium was held in 2013 and resulted in three papers aimed at supporting our community of education scholars. ${ }^{3-5}$ The first consensus paper defined education scholarship in EM and recommended that the academic section support the scholarship of education innovation. ${ }^{3}$ The second consensus paper called for support for education scholars through the creation of formal networks and positions, dedicated infrastructure, and financial support. ${ }^{4}$ The final consensus paper was a "how-to" guide that highlighted common pitfalls for those struggling to elevate an innovation to the standard of scholarship and disseminate their results. ${ }^{5}$

In response, the CAEP Academic Section developed the following initiatives. The Great Evidence in Medical Education Summaries (GEMeS) and Featured Educational Innovations (FEIs) initiatives were started to disseminate best practices in EM education to front-line clinicians and teachers. GEMeS is a venue to translate great papers from medical education for front-line clinician teachers, explaining how a more general education paper might change their bedside or classroom teaching practice. The FEIs allow clinician educators to share their local educational initiatives with our national (and international) colleagues. They are hosted on the CAEP website (http://caep.ca/CAEPGEMeS and http://caep.ca/CAEP_FEIs) and syndicated in the blogosphere via the CanadiEM website (https://canadiem. org). Additionally, a new CAEP conference abstract competition for education innovations was developed using an adjudication framework specific to education, and we have seen significant growth in abstracts submitted. For 2018, we received 33 education innovations and 34 education research abstracts. Finally, the CFEM Brief Educational Reports category was developed by the $C F E M$ editorial board to specifically profile and disseminate scholarly innovation.

\section{THE PRESENT: WE'VE COME A LONG WAY IN JUST 8 YEARS}

Nearly a decade later, we are reaping the benefits of developing and inspiring the next generation of EM education scholars. Figure 1 displays both the number of citations and papers published by Canadian EM educators affiliated with the CAEP Academic Section's Education Scholarship Committee. One needs to take only one look at the figure to see that our focus on education scholarship has yielded substantive outcomes over the past 10 years, growing from 8 publications and 125 citations in 2007 to 136 publications and 2,666 citations in 2017.

From the *Department of Emergency Medicine, University of Saskatchewan, Saskatoon, SK; and the tDivision of Emergency Medicine, Department of Medicine, McMaster University, Hamilton, ON.

Correspondence to: Dr. Rob Woods, Room 2689 Royal University Hospital, 107 Hospital Drive, Saskatoon, SK S7N 0W8, Canada; Email: rob.woods@ usask.ca 


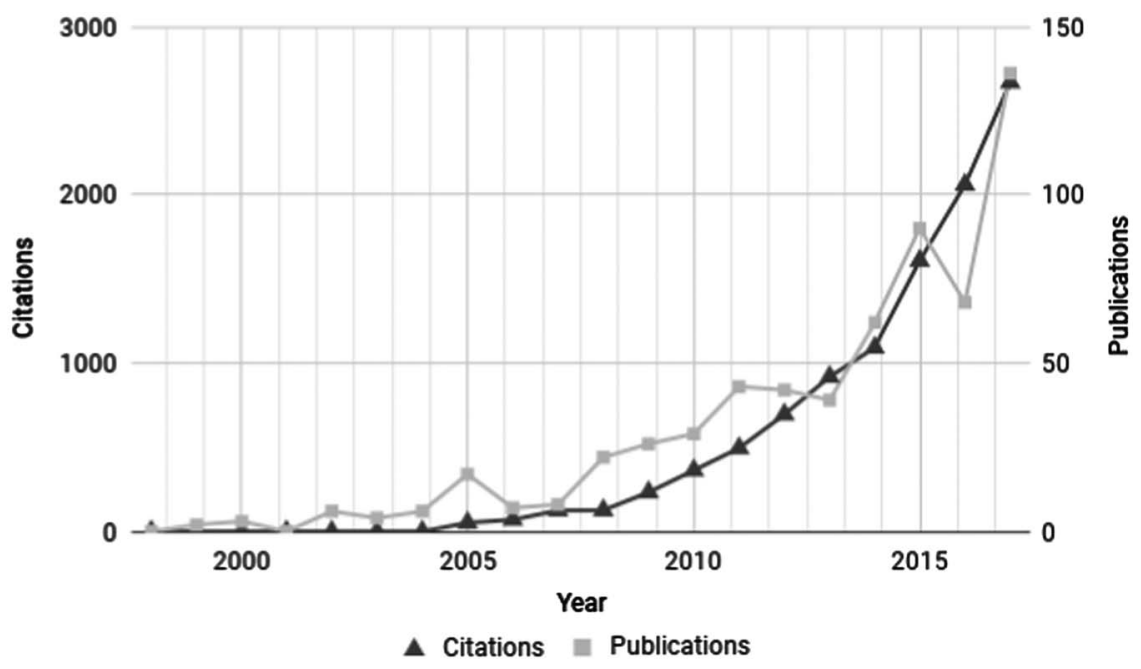

Figure 1. Medical education publications and their citations written by Canadian emergency physicians by year using metrics from Google Scholar.

Additionally, 2017 marked the launch of our specialty's first dedicated education journal (Academic Emergency Medicine Education and Training journal) that frequently features the work of Canadian EM education scholars. General medical education journals like Academic Medicine, Medical Teacher, and the Fournal of Graduate Medical Education have also featured Canadian EM scholars. Topics being explored by our community include the teaching of communication and interpersonal skills, utility of social media for teaching and learning, ultrasound education, simulation as an assessment or teaching tool, workplace- and competency-based assessments, and the science of trainee and expert EM clinician cognition.

However, the landscape has changed since 2010. Impact as an education scholar requires formal training and mentorship. ${ }^{6}$ This training can include a graduate degree, fellowship, or the new Royal College Area of Focused Competence Clinician Educator program. CAEP has supported the development of education scholars via the Clinician Educator Mentorship Service at the CAEP Annual Conference, the Academic Section Education Consultation Service for Divisions and Department of EM, and a second Academic Symposium on education scholarship in 2016. Building on the inaugural symposium, the 2016 symposium produced consensus guidelines on the training of future clinician educators, ${ }^{7}$ the development of educators and scholars with an impact on $\mathrm{EM},{ }^{6}$ and provided further guidance on the production of high quality medical education scholarship. ${ }^{1,8-11}$ These consensus guidelines suggest best practices to support the growth of the next generation of scholars.

\section{THE FUTURE: NEW CHALLENGES AND OPPORTUNITIES}

July 1, 2018 will mark a new chapter in Canadian EM education as we join the second cohort of Royal College disciplines to implement competency-based medical education (CBME) in residency education. With this transition, scholarship is essential to inform the rollout refinement of a completely different curriculum. The new emphasis on multiple, low stakes, workplace-based assessments is supported by emerging ${ }^{12-14}$ literature that asks more questions than it provides answers.

Beyond CBME, there are many other important questions to be answered, yet the big questions are hard, if not impossible, to address via a single institution study. Sherbino's challenge to stop "underpowered, opportunistic, one-off programs" and move towards a shared educational agenda through a community of practice has not been fully met. ${ }^{2}$ The development of more robust multi-site studies has been inhibited by logistical concerns such as the sharing of educational data, limited educationally oriented research operations funding to manage multi-site studies, competing local and national agendas, and the lack of consensus on research or scholarship priorities that will need to be addressed to make further progress.

Infrastructure like the Network of Canadian Emergency Researchers (NCER) may foster collaborative solutions to help overcome these issues. Because it was originally 
conceived to bring together clinical EM researchers to participate in national research initiatives, our educational scholars have yet to attend in a significant way. However, we believe that there is potential to collaborate with NCER to assist us with national education research agenda. To start, we have created a Google Scholar listing of the education scholarship published by our CAEP education scholarship committee members so that all of our members can stay informed of the great work that our members are doing. Members need only go to our new Google Scholar account website (https://scholar.google.ca/citations?hl= en\&user=g_0bCrcAAAAJ) and click the "Follow" icon to receive updates about exciting new medical education research from CAEP members.

\section{CONCLUSION}

The challenge for the EM community is to support the continued growth in EM education scholarship. By continuing to talent spot, develop, and support education scholars, we can answer the important questions in medical education. This will continually inform our educational practice to best prepare our trainees for the challenges of practicing in our specialty.

Keywords: development, education scholarship, emergency medicine, mentorship

Competing interests: None declared.

\section{REFERENCES}

1. Chan TM, Ting DK, Hall AK, et al. A writer's guide to education scholarship: qualitative education scholarship (part 2). C7EM 2018;20(2):284-92, doi:10.1017/cem. $\underline{2017.25}$.
2. Sherbino J. Education scholarship: the next step for our specialty. CFEM 2010;12(4):347-8.

3. Sherbino J, van Melle E, Bandiera G, et al. Education scholarship in emergency medicine part 1: innovating and improving teaching and learning. CFEM 2014;16(Suppl 1): S1-5, doi:10.2310/8000.2014.141454.

4. Bandiera G, Leblanc C, Regehr G, et al. Education scholarship in emergency medicine part 2: supporting and developing scholars. CFEM 2014;16(Suppl 1):S6-12, doi: $10.2310 / 8000.2014 .141455$.

5. Bhanji F, Cheng A, Frank JR, et al. Education scholarship in emergency medicine part 3: a "how-to" guide. CFEM 2014;16(Suppl 1):S13-8, doi:10.2310/8000.2014.141456.

6. Frank JR, Cheung WJ, Sherbino J, et al. CAEP 2016 academic symposium: how to have an impact as an emergency medicine educator and scholar. CFEM 2017;19(S1):S16-21, doi:10.1017/cem.2017.339.

7. Woods RA, Artz JD, Carrière B, et al. CAEP 2016 academic symposium on education scholarship: training our future clinician educators in emergency medicine. CFEM 2017; 19(S1):S1-8, doi:10.1017/cem.2017.41.

8. Chan TM, Thoma B, Hall AK, et al. CAEP 2016 academic symposium: a writer's guide to key steps in producing quality education scholarship. C7EM 2017;19(S1):S9-15, doi:10.1017/cem.2017.30.

9. Thoma B, Camorlinga P, Chan TM, et al. A writer's guide to education scholarship: quantitative methodologies for medical education research (part 1). CFEM 2018;20(1): 125-31, doi:10.1017/cem.2017.17.

10. Murnaghan A, Weersink K, Thoma B, et al. A writer's guide to education scholarship in emergency medicine: systematic reviews and the scholarship of integration (part 4). C7EM 2017; epub, doi:10.1017/cem.2017.29.

11. Hall AK, Hagel C, Chan TM, et al. A writer's guide to education scholarship in emergency medicine: education innovations (part 3). CFEM 2017; epub, doi:10.1017/cem.2017.28.

12. Chan T, Sherbino J. The McMaster Modular Assessment Program (McMAP). Acad Med 2015;90(7):900-5, doi:10.1097/ACM.0000000000000707.

13. McConnell M, Sherbino J, Chan TM. Mind the gap: the prospects of missing data. 7 Grad Med Educ 2016;8(5): 708-12, doi:10.4300/JGME-D-16-00142.1.

14. Chan TM, Sherbino J, Mercuri M. Nuance and noise: lessons learned from longitudinal aggregated assessment data. 7 Grad Med Educ 2017;9(6):724-9. 